\title{
Federalismo e conselhos de assistência social: uma análise a partir do financiamento
}

\author{
Edite da Penha Cunha ${ }^{1}$ (D) \\ Isabella Lourenço Lins² (D) \\ Márcia Miranda Soares ${ }^{3}$
}

\begin{abstract}
Federalismo e participação social são temas relevantes nos estudos de políticas públicas. Contudo, nota-se pouco diálogo entre esses temas, lacuna que este artigo busca minimizar ao analisar os efeitos do centralismo fiscal da assistência social no funcionamento e no resultado produzidos pelos conselhos. A dinâmica federativa dessa política se reproduziria também nos conselhos, diferenciando as instituições nacionais e subnacionais? Para responder a essa questão, o artigo adota análise qualitativa para identificar fortalecimento ou constrangimento do centralismo fiscal em trechos de 658 atas e 2.364 resoluções de cinco casos: o CNAS; os conselhos estaduais de Minas Gerais e Rio Grande do Sul; e os conselhos municipais de Belo Horizonte e Porto Alegre. Os resultados apontam que a forte regulamentação da assistência social e a concentração de gastos no nível central têm importantes efeitos, promovendo o fortalecimento do CNAS e constrangimentos à atuação dos conselhos subnacionais na definição e controle dessa política em seu financiamento.

Palavras-chave: federalismo; instituições participativas; conselhos de políticas públicas; assistência social; financiamento
\end{abstract}

\section{Introdução}

Este artigo busca contribuir para uma agenda de pesquisa que associe federalismo, instituição tradicional do sistema político que tem vigência formal no Brasil desde 1889, e instituições de participação social (IPs), novo tipo de institucionalidade que ganha destaque a partir da nova ordem constitucional brasileira. A IP considerada neste artigo é o conselho de assistência social. O objetivo é verificar os efeitos do centralismo fiscal, expresso na regulamentação e execução de gastos da União com a assistência social, no funcionamento

\footnotetext{
1 Universidade Federal de Minas Gerais, Departamento de Ciência Política. Belo Horizonte (MG), Brasil. E-mail: <edite_cunha@yahoo.com.br>.

2 Universidade Federal de Minas Gerais, Departamento de Ciência Política. Belo Horizonte (MG), Brasil. E-mail: <bellalins2017@gmail.com>.

3 Universidade Federal de Minas Gerais, Departamento de Ciência Política. Belo Horizonte (MG), Brasil. E-mail:<marciamsoares@uol.com.br>.
} 
EDITE DA PENHA CUNHA; ISABELLA LOURENÇO LINS; MÁRCIA MIRANDA SOARES

e resultado dessas instituições no âmbito nacional, estadual e municipal, no período de 2003 a 2010, quando essa política passou a ser priorizada na agenda pública. Com esse propósito, a questão que norteia o artigo é: como a organização federativa da política de assistência social, marcada pelo centralismo fiscal, afeta o funcionamento e o resultado dos conselhos de assistência social?

No Brasil, os estudos sobre federalismo e participação social prosperaram, nas últimas décadas, na ciência política em decorrência da redemocratização e dos desafios trazidos para as políticas públicas em um país marcado pela autonomia política dos estados e municípios. A agenda de federalismo aprofundou o conhecimento sobre os efeitos dessa forma de organizar o Estado nacional para as políticas sociais. Já a agenda de participação social tem como um dos seus focos de análise os conselhos de políticas públicas, denominados pela literatura como Instituições Participativas (IPs), que se distinguem como "formas diferenciadas de incorporação de cidadãos e associações da sociedade civil na deliberação sobre políticas" (Avritzer, 2008, p. 45). Contudo, os estudos que conectam essas agendas são escassos, valendo mencionar nesse aspecto os trabalhos de Lavalle e Barone (2015) e Lavalle, Voigt e Serafim (2016).

$\mathrm{Na}$ busca de articulação entre federalismo e IPs, pode-se adotar a metáfora do "enxerto" de Wampler (2011), que sugere novos estudos que extrapolem os limites internos das instituições participativas e as situem em contextos mais amplos (políticopartidário, associativo, econômico, normativo-legal, entre outros). Nessa direção, a atuação das IPs impacta as políticas públicas e os contextos nos quais estão inseridas, assim como "são influenciadas, condicionadas e têm suas possibilidades e limites de atuação determinados pelos próprios contextos e estruturas institucionais em que se inserem" (Pires et al., 2011, p. 356). Essa é a perspectiva analítica deste artigo, que tem no federalismo uma instituição do sistema político tradicional que influencia as novas institucionalidades porque estabelece as regras do jogo (polity) no qual os atores interagem e tomam decisões, em determinado contexto político (politcs) (Hall e Taylor, 2003). Dessa forma, o federalismo pode tanto impor constrangimento, entendido aqui como a limitação da capacidade decisória e do controle exercidos pelos conselhos sobre o financiamento da política, quanto fortalecer a atuação dos conselhos, ou seja, promover a garantia e/ou a ampliação da capacidade destes para decidir e controlar o financiamento.

O pressuposto geral é de que a centralização da assistência social, caracterizada aqui em sua dimensão fiscal, fator estruturante na conformação e no desenvolvimento dessa política, se reflete nas IPs, centralizando poder no Conselho Nacional de Assistência Social (CNAS) e conformando a discussão e as decisões dos conselhos estaduais e municipais de assistência social.

A metodologia adotada para testar esse pressuposto foi a análise descritiva do funcionamento e do resultado dos conselhos na temática do Financiamento da assistência social. Foi realizada a análise de conteúdo de leis, decretos, portarias e instruções normativas do MDS (Ministério do Desenvolvimento Social e Combate à Fome), atas e 
resoluções de cinco casos selecionados: o CNAS; os conselhos estaduais de assistência social de Minas Gerais (MG) e Rio Grande do Sul (RS); e os conselhos municipais de Belo Horizonte $(\mathrm{BH})$ e Porto Alegre (PoA). A escolha dos casos foi necessária diante do volume de documentos que são produzidos pelas IPs e da profundidade pretendida para a investigação. O CNAS é único e central na análise da dinâmica federativa nas IPs, já os municípios de BH e PoA foram escolhidos por representarem casos similares (Seawright e Gerring, 2008). Esses municípios apresentam trajetória de projetos políticos participativos e relações entre sociedade civil e Estado marcadas pela criação e continuidade das primeiras experiências de participação institucionalizada na assistência social. A escolha das IPs estaduais decorreu da localização dos municípios selecionados, contemplando os três níveis de governo.

O período analisado, de 2003 a 2010, justifica-se pela necessidade de delimitar o escopo da pesquisa, pela disponibilidade dos documentos e, ainda, por ter sido marcado por um forte processo de coordenação federativa na assistência social, exercido pelo MDS, e pelo incentivo e ampliação da participação social institucionalizada durante a gestão do Partido dos Trabalhadores (PT). É quando o governo central faz uso de seus poderes institucionais, como a centralização jurisdicional, para promover mudanças substantivas na assistência social. Assim, é no período selecionado que se tem a aprovação e implantação de normativas que estabeleceram as bases de criação e estruturação do Sistema Único de Assistência Social (Suas).

Se na literatura sobre federalismo fiscal mais tradicional é enfatizada a participação dos governos subnacionais nas receitas e nos gastos públicos como principais indicadores de centralização ou descentralização fiscal, na mais recente entende-se que é preciso ir além desses aspectos. É exemplar dessa perspectiva o trabalho de Rodden (2005), que, ao revisar a literatura sobre o tema, sustenta que é preciso considerar "a estrutura regulatória das finanças subnacionais", já que "a descentralização do gasto governamental pode dizer muito pouco sobre o lócus da autoridade" (p. 11). Essa é a perspectiva adotada neste artigo, que considera a expressiva produção normativa nacional sobre o financiamento da política de assistência social e o aumento substantivo dos gastos da União para caracterizar o centralismo fiscal. Centralismo que pode ter influenciado a atuação dos conselhos nos diferentes níveis de governo na discussão e nas decisões sobre a política na temática do financiamento.

O artigo está estruturado em quatro seções: na seção que se segue a esta Introdução, "Federalismo, instituições participativas e centralismo fiscal na assistência social brasileira", tem-se uma breve revisão bibliográfica que apresenta aspectos do federalismo brasileiro e das IPs na atual ordem constitucional, tendo destaque a configuração do federalismo na política de assistência social, marcada pela centralização fiscal. Na seção seguinte, "Efeitos do centralismo fiscal no funcionamento e resultados dos conselhos de assistência social", é apresentada a estratégia metodológica utilizada e os resultados encontrados sobre os efeitos do centralismo fiscal no funcionamento e resultado 
EDITE DA PENHA CUNHA; ISABELLA LOURENÇO LINS; MÁRCIA MIRANDA SOARES

dos conselhos. Por fim, nas "Conclusões" discutem-se os resultados da pesquisa e as perspectivas para novos estudos.

\section{Federalismo, instituições participativas e centralismo fiscal na assistência social brasileira}

O federalismo é fator institucional relevante para compreender as políticas públicas, destacadamente as sociais (Pierson, 1995; Arretche, 2004, 2012; Abrucio, 2006), o que não difere para o caso da assistência social brasileira, no qual a União teve um papel fundamental na constituição de um sistema nacional com vistas a coordenar as ações dos entes governamentais, o Suas. Um aspecto pouco claro dos efeitos dessa dinâmica federativa se refere às instituições participativas que integram a política, objeto a que este artigo se dedica.

O modelo federativo brasileiro na ordem constitucional iniciada em 1988 tem como grande novidade o status constitucional alcançado pelos municípios. A federação de três níveis de governo, com distribuição de poderes políticos, fiscais e administrativos entre União, estados e municípios, foi um elemento adicional na estruturação de um sistema político com elevada dispersão do poder, considerando ainda elementos como o presidencialismo, o bicameralismo, eleições proporcionais para o Legislativo, entre outros. Cientes disso e temendo efeitos negativos para a estabilidade democrática, os constituintes buscaram garantir alguns poderes ao Executivo nacional, destacadamente o poder de agenda na produção legislativa, inclusive na questão fiscal (Limongi, 2008).

Esse aspecto centralizador, que contrasta com outros de dispersão de poder, teve efeitos importantes na conformação e desenvolvimento das políticas sociais, principalmente a partir de meados dos anos 1990, com a estabilização da moeda e o avanço de medidas legislativas do Executivo para fortalecer suas finanças e fazer avançar os amplos direitos sociais previstos no texto constitucional, dentre os quais se situa a assistência social. Conforme Arretche (2009) e Soares e Machado (2016), a CF-88 dotou a União de poderes para iniciar legislação de interesse próprio e para regulamentar competências administrativas e fiscais dos entes subnacionais, inclusive sobre as políticas sociais, sem precisar de supermaiorias para aprovar tais propostas. Arretche (2012) aponta que o governo central, com seu poder de legislar e financiar políticas sociais, reteve boa parte da autoridade decisória de formulação das políticas públicas (policy decisionmaking), cabendo aos entes subnacionais, principalmente aos municípios, o poder de implementar as políticas (policy-making), sem desconsiderar que esse último poder também envolve decisões e reformulações da política.

O federalismo brasileiro atual, portanto, é caracterizado por grande poder de normatização da União (centralização jurisdicional), que se faz presente na dimensão fiscal, seja na política tributária, seja na definição dos gastos públicos. Além de poder definir, via normas, o financiamento das políticas públicas, o governo central tem alta 
capacidade de realizar gastos com estas, podendo expandir ou recuar em seu financiamento. Essas duas dimensões - o poder de normatizar e o de executar gastos da União - configuram o centralismo fiscal no federalismo brasileiro. Com isso, a União pode induzir comportamentos subnacionais em relação a uma determinada política, especialmente quando faz uso de legislação nacional vinculante aos entes subnacionais e de transferências intergovernamentais condicionadas para as políticas sociais, com destaque para saúde, educação e assistência social. Nesse último aspecto, o mecanismo principal utilizado tem sido as transferências legais fundo a fundo, que são transferências de um fundo nacional setorial para outro fundo subnacional setorial, de acordo com as regras estabelecidas em lei, ou seja, são transferências condicionadas. Há ainda as transferências diretas de renda aos cidadãos por meio do Benefício de Prestação Continuada (BPC) e do Programa Bolsa Família (PBF), que possuem dinâmicas ainda mais centralizadas na União.

Outra dimensão importante da configuração política do país é a participação social. E a maior novidade nesse aspecto foi a sua valorização e a criação de canais permanentes para sua ocorrência. Com isso, têm-se as IPs, que podem ser caracterizadas como "mecanismos de participação criados por lei, emendas constitucionais, resoluções ou normas administrativas governamentais que permitem envolvimento regular e continuado de cidadãos com a administração pública" (Cortes, 2011, p. 137). No Brasil, três modelos de participação institucionalizada tornaram-se predominantes: o orçamento participativo, os conselhos e as conferências de políticas públicas. O artigo analisa um tipo de IP, os conselhos, organizados nos três entes federados, sob a influência da dinâmica política nacional.

Os conselhos de políticas públicas emergem como inovações institucionais participativas destinadas a influir nas decisões estatais mediante o exercício de competências conferidas pelas leis que os criaram e definiram seu campo de atuação (Tatagiba, 2002). Instituídos como forma de participação e deliberação no campo das políticas públicas pós-Constituição de 1988, exercem duas principais funções: a de democratizar a tomada de decisão no que diz respeito à formulação de políticas públicas e a de controlar e fiscalizar a execução dessas políticas, destacadamente na utilização dos recursos públicos.

Ainda que compartilhem algumas características, os conselhos de políticas se diferenciam em relação à origem, à composição, às atribuições formais e ao poder de influência nas decisões estatais. Assim, os conselhos de assistência social devem seguir tanto suas competências definidas em legislação específica quanto as orientações constantes da Norma Operacional Básica (NOB)/Suas, que reafirmam a participação popular como um dos eixos estruturantes do Suas e reforçam a vinculação dos conselhos ao órgão gestor da política, em cada nível federativo, o qual deve Ihes dar condições de funcionamento. Essa norma especifica com mais clareza as atribuições e competências dos conselhos de cada nível de governo, que consistem 
em: (1) estabelecer diretrizes e aprovar a política; (2) acompanhar e controlar a sua execução; (3) acompanhar e avaliar o desempenho dos programas e projetos; (4) aprovar, acompanhar e controlar a execução do plano plurianual e do plano anual de ação; (5) aprovar a proposta orçamentária dos recursos destinados às ações finalísticas da política, alocados no fundo de assistência social; (6) aprovar o plano de aplicação desse fundo e acompanhar a execução orçamentária e financeira anual dos recursos; (7) normatizar as ações e regular a prestação de serviços; (8) convocar as conferências de assistência social; (9) zelar pela efetivação do Suas.

O termo "controle social" enseja diversas definições para a participação das IPs nas políticas públicas e abrange a decisão e o controle sobre o financiamento destas (Cunha, 2018). Neste artigo, delimitou-se a análise da participação dos conselhos de assistência social na definição da proposta orçamentária da área e dos programas do fundo, na aprovação dos critérios de transferência de recursos para os entes subnacionais e entidades e organizações de assistência social, e no acompanhamento da execução dos recursos, dos gastos e na emissão de pareceres sobre as prestações de contas do fundo.

O centralismo jurisdicional da União, com destaque para sua dimensão fiscal, o que inclui a criação de mecanismos de repasse de recursos condicionados à criação e ao efetivo funcionamento das IPs, foi fundamental para a expansão dos conselhos em diferentes áreas de políticas públicas (Arretche,1999, 2002; Abrucio, 2006), mas isso não ocorreu de forma uniforme. Lavalle e Barone (2015) demonstram três padrões de evolução territorial dos conselhos municipais, entre 1989 e 2009, associados a graus distintos de indução federal, que ocorre, sobretudo, por meio de transferências de recursos fundo a fundo, tendo como uma das condicionalidades a institucionalização da participação social. Os autores identificam conselhos: (1) que tenderam à universalização em todo o país, impulsionados por mecanismos fortes de indução federal, notadamente os repasses condicionados; (2) com expansão média, estimulados por modalidades moderadas de indução federal; (3) com presença territorial baixa, associados a formas de indução federal fracas. Lavalle, Voigt e Serafim (2016), a partir de uma análise da produção decisória dos conselhos, apontam também a presença de atividade decisória consideravelmente mais elevada nos conselhos com alta indução federal.

O presente artigo busca avançar na análise do efeito da dinâmica federativa sobre as IPs a partir do exame de como o financiamento da política de assistência social, que sofre o efeito direto do centralismo fiscal do federalismo brasileiro, influencia o funcionamento e o resultado dos conselhos de políticas públicas. O funcionamento é uma dimensão de análise central nos estudos sobre IPs, dado que importa saber não apenas quem participa e decide nesses espaços, mas, principalmente, como e sobre o que se delibera (Pires et al., 2011). Em relação ao resultado produzido pelos conselhos, este corresponde às decisões transformadas em resoluções, sendo também uma dimensão de análise importante porque expressa a capacidade efetiva das IPs de influenciar 
determinada política pública.

A assistência social passou por alterações profundas, destacadamente a partir de 2003, quando o Executivo nacional a assume como política prioritária de governo e, utilizando os instrumentos institucionais que o federalismo the proporciona, passa a exercer o papel de coordenador perante outros entes de governo. Em 2004, no governo Lula, o Ministério do Desenvolvimento Social e Combate à Fome (MDS), atendendo às deliberações da IV Conferência Nacional de Assistência Social, revisou a Política Nacional de Assistência Social (PNAS), que produziu as bases conceituais e estabeleceu os princípios, diretrizes e objetivos que nortearam a criação e a implantação do Suas. Para operacionalizar a participação da sociedade civil na assistência social, a Loas (1993) estabeleceu dois espaços institucionalizados de participação e deliberação: os conselhos e as conferências. Essa lei instituiu o Conselho Nacional de Assistência Social (CNAS), os Conselhos Estaduais de Assistência Social (Ceas), o Conselho de Assistência Social do Distrito Federal e os Conselhos Municipais de Assistência Social (CMAS), todos devendo ser dotados de caráter permanente, deliberativo e de composição paritária entre governo e sociedade civil.

A política de assistência social é relevante para a análise em questão, que busca articular federalismo e participação social institucionalizada, porque está organizada em um sistema nacional de provisão de serviços públicos nos três níveis de governo, o que envolve cofinaciamento e fundos setoriais, e também porque conta com um processo decisório participativo. Ainda, é uma política que evoluiu em pouco espaço de tempo e de forma abrangente a partir de 2003, quando o Executivo nacional se utiliza de seu poder de normatizar e gastar para fazê-la avançar em todo o território.

Em relação à regulamentação, tem-se definido no artigo 204 da CF/88 que o financiamento da política será realizado com recursos do orçamento da Seguridade Social, previstos no art. 195, além de outras fontes. Tanto a Constituição como a Loas, em seu artigo 28, determinam a responsabilidade do Poder Público no financiamento dos benefícios, serviços, programas e projetos de assistência social. As diretrizes da PNAS/2004 e da NOB/Suas 2005 reiteraram o financiamento compartilhado entre os três entes e estabeleceram critérios de partilha e regras de cofinanciamento. A Loas determinou a criação de fundos especiais de assistência social, o que foi reforçado na PNAS, que definiu sua existência nas três esferas de governo a partir de recursos próprios dos governos e repasses intergovernamentais.

A NOB (2005) também definiu a segmentação das transferências dos recursos do Fundo Nacional de Assistência Social (FNAS) sob a forma de pisos de proteção social, que passaram a ser adotados conforme o nível de complexidade das proteções e os diferentes tipos de gestão (inicial, básica e plena). Esses pisos foram adequados à Tipificação Nacional de Serviços Socioassistenciais, instituída em 2009, que organizou a oferta de atenções da política de assistência social por níveis de complexidade e de proteção (básica, média e alta complexidade). 
Em termos de distribuição das competências de financiamento, a Loas estabelece que compete à União a concessão e a manutenção dos benefícios de prestação continuada e o apoio financeiro aos serviços, programas e projetos de enfrentamento da pobreza em âmbito nacional (art. 12). Aos estados compete a destinação de recursos financeiros aos municípios, a título de participação no custeio do pagamento dos benefícios eventuais; o apoio financeiro aos serviços, programas e projetos de enfrentamento da pobreza em âmbito regional ou local; e o apoio financeiro a associações e consórcios municipais na prestação de serviços (art. 13). Ao Distrito Federal e aos municípios compete destinar recursos financeiros para o pagamento dos benefícios eventuais e prestar serviços assistenciais (arts. 14 e 15). Destaque-se que a Lei no 10.954, de 29 de setembro de 2004, determinou que compete à União financiar, em conjunto com os entes subnacionais, as ações assistenciais de caráter emergencial.

A União não somente centralizou a regulamentação do financiamento da assistência social, como também a execução dos gastos. Castro et al. (2012) verificaram, para o período de 1995 a 2010, que a assistência social foi a área social que, proporcionalmente, obteve maior crescimento de gastos federais em percentual do produto interno bruto brasileiro (PIB). Passou de 0,08\% em 1995, para 0,66\% em 2003 e para $1,07 \%$ em 2010. A razão principal para esse crescimento foi a implantação do BPC e a rápida expansão do PBF na segunda metade do período. Em termos de evolução dos gastos entre os entes no período de 2003 a 2010, os gastos da União passaram de 8,4 para 39,1 bilhões, o dos estados, de 2,2 para 4,0 bilhões e o dos municípios, de 3,5 para 8,9 bilhões ${ }^{4}$. Com isso, tem-se um quadro de amplo crescimento dos gastos com a política liderado pela União, seguido pelos municípios e, por fim, pelos estados.

\section{Efeitos do centralismo fiscal no funcionamento e resultados dos conselhos de assistência social}

\section{Metodologia}

Compreende-se que o centralismo fiscal pode ter dois efeitos sobre a atuação dos conselhos de assistência social: constrangimento e fortalecimento. O primeiro é entendido como a limitação da capacidade decisória e do controle exercidos pelos conselhos subnacionais sobre o financiamento da política, e o segundo efeito é o fortalecimento, compreendido como a garantia e/ou a ampliação da capacidade dos conselhos para decidir e controlar o financiamento.

Tendo como pressuposto que o centralismo fiscal - regulamentação do financiamento e capacidade de gasto da União com a política - fortalece o Conselho Nacional de Assistência Social e constrange os conselhos subnacionais de participarem da

\footnotetext{
4 Valores deflacionados para a data de 31 de dezembro de 2010 a partir do Índice de Preços ao Consumidor (IPCA).
} 
decisão e do controle do financiamento da assistência social, o Quadro 1 apresenta os efeitos esperados nos casos selecionados para análise.

Observe que, na dimensão do funcionamento, espera-se o fortalecimento do CNAS, ou seja, a capacidade do conselho nacional para definir e controlar o financiamento é fortalecida pelo centralismo fiscal, uma vez que cabe à União o papel preponderante de regular e executar os gastos com a política. No caso dos conselhos subnacionais, espera-se que a capacidade destes para definir e controlar o financiamento seja constrangida pelo centralismo fiscal, visto que muitos entes subnacionais, para receberem recursos do FNAS para a execução da política em seus âmbitos, devem se vincular a decisões tomadas no âmbito nacional.

Em relação ao resultado produzido pelos conselhos, a direção seria a mesma do funcionamento, espera-se que as decisões produzidas pelo conselho nacional expressem o efeito de fortalecimento deste pelo centralismo fiscal, enquanto as decisões produzidas pelos conselhos subnacionais expressem 0 efeito de constrangimento desse centralismo.

Quadro 1
$\begin{aligned} & \text { Dimensões de análise e efeitos esperados do centralismo } \\
& \text { fiscal sobre os conselhos de assistência social }\end{aligned}$
\begin{tabular}{|l|c|c|}
\hline $\begin{array}{l}\text { Dimensões dos } \\
\text { conselhos }\end{array}$ & $\begin{array}{c}\text { Nível dos } \\
\text { conselhos }\end{array}$ & Efeitos esperados \\
\hline \multirow{2}{*}{ Funcionamento } & Nacional & Fortalecimento \\
\cline { 2 - 3 } & Subnacionais & Constrangimento \\
\hline \multirow{2}{*}{ Resultado } & Nacional & Fortalecimento \\
\cline { 2 - 3 } & Subnacionais & Constrangimento \\
\hline
\end{tabular}

Fonte: Elaboração própria.

Para captar os efeitos, a pesquisa adotou técnicas de análise de conteúdo dos documentos para tratar o amplo material coletado: 49 leis, decretos, portarias e instruções normativas do MDS, 658 atas e 2.364 resoluções. Optou-se pela utilização do software NVivo para sistematização e análise dos dados.

A dimensão funcionamento foi pesquisada através das atas por meio da análise de seu conteúdo temático, que teve por finalidade identificar os temas constantes no processo deliberativo das IPs, sendo a presença e a frequência de determinado conteúdo significativas para a análise de seu funcionamento, conforme lembram Cunha (2007) e Almeida (2008).

Tendo em vista a grande variedade de assuntos sobre os quais as IPs discutem e decidem, desde questões relacionadas com sua organização interna até o planejamento e o controle da política pública, torna-se fundamental identificá-los. Conforme argumentam Cunha et al. (2011), a codificação dos temas que são discutidos pelas IPs possibilita mapear o processo deliberativo e estabelecer comparações entre elas no que tange à 
presença ou não das condições necessárias para sua efetividade deliberativa. Ainda, a análise das temáticas possibilita verificar se as IPs se aproximam ou se afastam do que é normativamente definido como suas atribuições (Pires et al., 2011). A unidade de registro escolhida para análise das atas e resoluções dos conselhos neste artigo foi, portanto, o tema. Sendo assim, classificou-se uma fala ou um conjunto de falas como uma frequência de vocalização de determinado tema.

Identificou-se que quatro temas, além do Financiamento, foram abordados com maior frequência pelos conselhos estudados: 1) Gestão da política - ações socioassistenciais, apoio técnico, gestão administrativa, normatização, gestão do trabalho como discussão da Norma Operacional Básica de Recursos Humanos (NOB RH), implantação de sistemas de informação, habilitação e desabilitação de municípios ao Suas, equipamentos públicos, planos, relatórios e avaliação; 2) Participação social - participação da sociedade em conferências, fóruns, audiências públicas, articulação com outros conselhos, órgãos gestores e entidades e ONGs, capacitação de conselheiros e incentivos à participação dos usuários; 3) Certificação de entidades - deferimento e/ou indeferimento de recursos e a normatização do processo de certificação; e 4) Inscrição de entidades - solicitação, aprovação, manutenção, suspensão ou o cancelamento e normatização desses processos. O tema Financiamento apareceu em 1.215 trechos de atas, sendo que, no CNAS, foi o terceiro tema mais debatido (19\%); nos conselhos estaduais, foi o segundo mais discutido: $25 \%$ no Ceas MG e $24 \%$ no Ceas RS; e, no âmbito municipal, foi o tema mais debatido, com 36\% das discussões no CMAS BH e CMAS PoA.

Já a dimensão de resultado produzido pelos conselhos foi analisada por meio das resoluções, sendo feita a classificação do conteúdo destas a partir dos mesmos cinco temas: Financiamento, Gestão, Participação social, Certificação e Inscrição. Enquanto os conteúdos das atas referiam-se a discussões relacionadas a diversos dos temas elencados, as resoluções tratavam do registro de decisões referentes a apenas um desses temas. Das 2.364 resoluções coletadas, identificou-se que 1.066 (45\%) trataram do tema Financiamento, constituindo-se, portanto, na amostra de análise para resultado produzido pelos conselhos. Verificou-se que esse tema correspondeu ao segundo mais identificado nas resoluções do CNAS (59 resoluções); enquanto nos conselhos estaduais foi o segundo tema mais presente no caso do Ceas MG (85 resoluções) e o primeiro no Ceas RS (136 resoluções); já nos munícipios foi o tema mais identificado nos dois casos, 271 no CMAS $\mathrm{BH}$ e 515 no CMAS PoA.

Os dados mostram a importância do financiamento para a dinâmica de discussão e deliberação dessas IPs, o que reforça a propriedade do tema escolhido. Os conteúdos das atas e resoluções relacionados ao tema Financiamento foram reclassificados, o que resultou em cinco subtemas relacionados a três aspectos: elaboração de proposta orçamentária (1- Orçamento); decisão e controle sobre a execução dos gastos nas ações socioassistenciais (2- Benefício de Prestação Continuada, 3- Benefícios eventuais e 4- 
Serviços, programas e projetos); e controle da prestação de contas dos recursos do FNAS (5- Prestação de contas) ${ }^{5}$.

A proxy para centralismo fiscal foi a legislação nacional produzida sobre o financiamento da política, sendo essa a referência para analisar cada trecho e identificar se a regra estabelecida para o subtema gerou constrangimento ou não à atuação dos conselhos. Em alguns casos, também foi possível mobilizar o aspecto de gasto do centralismo fiscal para analisar seu efeito sobre as IPs. Para o CNAS, nos trechos em que se identificou a confirmação do pressuposto de que o centralismo fortalece a capacidade do conselho nacional para decidir e controlar o financiamento federal, ou seja, situações que denotavam uma atuação desse conselho na elaboração do orçamento e no controle da execução e dos recursos do FNAS, atribuiu-se o código 1. Um exemplo de situação de confirmação do pressuposto verificou-se ao se observar o CNAS definindo procedimentos e parâmetros para elaboração, análise e aprovação do orçamento e critérios de partilha e de transferência de recursos.

Naqueles trechos em que não se identificou que o centralismo fiscal fortaleceu o conselho nacional, tendo efeito nulo ou contrário ao esperado (constrangimento), atribuiuse o código 0 . Um exemplo de situação de não confirmação do pressuposto é a exigência de Certidão Negativa de Débitos (CND) para a efetivação dos repasses entre entes federados. Outro exemplo são as regras gerais do processo orçamentário que impõem prazos e procedimentos específicos.

$\mathrm{Na}$ análise dos conselhos subnacionais, atribuiu-se o código 1 para as situações em que se identificou que a legislação nacional sobre o subtema limitou a capacidade desses conselhos para decidir e controlar os recursos do FNAS, confirmando, assim, o pressuposto de que o centralismo inibe a atuação das IPs subnacionais. Um exemplo é o registro de menções sobre a impossibilidade de os conselheiros subnacionais discutirem a previsão e a destinação de recursos federais. Diversamente, o código 0 foi atribuído para situações em que não se identificou que o centralismo fiscal tenha limitado os conselhos subnacionais, tendo efeito nulo ou contrário ao esperado (fortalecimento). Um exemplo é quando a legislação nacional fortalece as competências fiscais dos conselhos subnacionais perante seus gestores, ao condicionar os repasses dos recursos para os entes subnacionais ao parecer do respectivo conselho. Outro exemplo, nesse caso de neutralidade, é quando o centralismo não abarca os entes subnacionais e gestores, e os conselhos têm autonomia para definir fontes e formas de controle de seus recursos próprios.

\section{Resultados}

Os resultados da pesquisa são apresentados abaixo para cada subtema de Financiamento, e, na sequência, os efeitos encontrados do centralismo sobre os conselhos,

\footnotetext{
5 Para mais informações sobre essa codificação, vide o Anexo.
} 
conforme classificação dos trechos e as dimensões analisadas.

\section{A atuação dos conselhos na elaboração de propostas orçamentárias}

A proposta orçamentária da assistência social, elaborada inicialmente pelo Poder Executivo nos três níveis de governo, deve ser apreciada pelo respectivo conselho, que posteriormente acompanhará a sua tramitação no Legislativo. A participação do conselho nesse processo depende muito do Executivo, que deve enviar, em tempo hábil, todas as informações quanto aos recursos previstos para a política. Identificaram-se, na análise das atas, 180 trechos relativos à "Elaboração de proposta orçamentária", com variações significativas entre os conselhos, conforme Quadro 2, evidenciando sua maior incidência nas discussões do CNAS e menor frequência nos conselhos subnacionais.

Os conselheiros nacionais discutiram e acompanharam todo o processo orçamentário da União, desde a formulação da proposta pelo Executivo até a tramitação no Legislativo, o que pode ser explicado pelo centralismo do gasto de assistência social na União. As atas também evidenciaram a evolução substancial desse gasto, alterando a dinâmica de discussões do CNAS, que passou a incorporar com maior frequência em suas reuniões questões relacionadas à formulação e à execução do orçamento e a intensificar as articulações com o Legislativo para assegurar os recursos necessários à implantação do Suas.

No caso do CNAS, dentre os 93 trechos classificados nesse subtema, observou-se em $74(80 \%)$ que o centralismo fiscal (em seu aspecto jurisdicional) fortaleceu a capacidade desse conselho para definir o financiamento. A maior atuação do conselho nacional foi expressa na indicação anual de parâmetros para o processo de elaboração, na análise e na aprovação da proposta orçamentária do Executivo para a área6 ${ }^{6}$ em especial do FNAS, antes de esta seguir para o Legislativo. Em outros 19 trechos (20\%), o centralismo fiscal não fortaleceu o CNAS, tendo efeito nulo ou mesmo de constrangimento, ocasionado por regras gerais do processo orçamentário e do Ministério do Planejamento, assim como a não vinculação de receita para a assistência social, que coloca o financiamento dessa política vulnerável a contextos e atores políticos.

$\mathrm{Na}$ análise do resultado deliberativo do conselho nacional para o subtema, identificaram-se 15 resoluções sobre a aprovação das propostas orçamentárias apresentadas pelo Executivo, com recomendações e ressalvas, além de sugestões de parâmetros para a elaboração e apresentação dos projetos de leis orçamentárias ao Poder Legislativo?.

\footnotetext{
6 A iniciativa das leis orçamentárias é do Poder Executivo, que apresenta a proposta por meio de projetos de lei ao Poder Legislativo, responsável por apreciar e emendar as propostas que, após aprovação final, serão publicadas em formato de lei.

7 A CF/88, em seu art. 165, determina a elaboração do orçamento público, nos entes federados, por meio de três peças legislativas: o Plano Plurianual (PPA), a Lei de Diretrizes Orçamentárias (LDO) e a Lei Orçamentária Anual (LOA).
} 
Nos conselhos subnacionais, observou-se no Ceas MG a maior frequência de discussão sobre as propostas orçamentárias, com 35 ocorrências (40\%) nas atas, enquanto no Rio Grande do Sul foram encontrados apenas 16 trechos (18\%). O conselho municipal de $\mathrm{BH}$ também apresentou uma frequência maior de discussões acerca da questão orçamentária em comparação com PoA, com, respectivamente, 26 (30\%) e 10 $(12 \%)$ trechos. Em relação aos efeitos do centralismo fiscal, dada a autonomia dos entes subnacionais para elaborar seus orçamentos, não se identificaram constrangimentos colocados pela legislação federal aos conselhos estaduais e municipais. Contudo, no que diz respeito à regulação dos recursos federais destinados aos fundos estaduais e municipais, confirmou-se o pressuposto de constrangimento do centralismo fiscal. A definição dos recursos federais para as ações da assistência social fica a cargo da União, não cabendo ingerência dos conselhos subnacionais, que não têm poder de modificar os valores nem sua destinação.

De forma congruente com o observado nas atas (funcionamento) dos conselhos, também foram encontrados efeitos de constrangimento do centralismo nos resultados deliberativos produzidos pelos conselhos subnacionais (17 resoluções). As resoluções dos conselhos tendem a estar alinhadas ao que se discute nas plenárias, e, no caso do Ceas RS, que não apresentou nenhuma resolução, ocorreram reiteradas cobranças de envio das propostas orçamentárias pelo Executivo, algo que não era realizado. A definição dos recursos federais para as ações da política de assistência social, como BPC, Bolsa Família e FNAS, fica a cargo do governo federal e de seu respectivo conselho, não cabendo a participação dos conselhos subnacionais. Esses conselhos discutem e decidem acerca das propostas orçamentárias de seus respectivos entes, e fazem isso de maneira mais restrita que o CNAS. Sendo assim, o centralismo fiscal fortaleceu a atuação do CNAS e não teve efeitos de fortalecimento captados sobre os conselhos subnacionais. 


\section{Quadro 2}

Efeitos do centralismo fiscal no subtema Proposta orçamentária, por conselho (2003-2010)

\begin{tabular}{|c|c|c|c|c|c|}
\hline Pressuposto & Conselho & $\begin{array}{c}\text { Dimensão de } \\
\text { análise }\end{array}$ & $\begin{array}{c}\text { Trechos de } \\
\text { confirmação do } \\
\text { pressuposto }\end{array}$ & $\begin{array}{c}\text { Trechos de não } \\
\text { confirmação do } \\
\text { pressuposto }\end{array}$ & $\begin{array}{c}\text { Total de } \\
\text { ocorrências }\end{array}$ \\
\hline \multirow{2}{*}{$\begin{array}{l}\text { Fortalecimento } \\
\text { pelo centralismo } \\
\text { fiscal }\end{array}$} & \multirow{2}{*}{ CNAS } & Funcionamento & 74 & 19 & 93 \\
\hline & & Resultado & 15 & 0 & 15 \\
\hline \multirow{8}{*}{$\begin{array}{l}\text { Constrangimento } \\
\text { pelo centralismo } \\
\text { fiscal }\end{array}$} & \multirow{2}{*}{ CEAS MG } & Funcionamento & 35 & 0 & 35 \\
\hline & & Resultado & 3 & 0 & 3 \\
\hline & \multirow{2}{*}{ CEAS RS } & Funcionamento & 16 & 0 & 16 \\
\hline & & Resultado & - & 0 & - \\
\hline & \multirow{2}{*}{ CMAS BH } & Funcionamento & 26 & 0 & 26 \\
\hline & & Resultado & 8 & 0 & 8 \\
\hline & \multirow{2}{*}{$\begin{array}{l}\text { CMAS } \\
\text { POA }\end{array}$} & Funcionamento & 10 & 0 & 10 \\
\hline & & Resultado & 6 & 0 & 6 \\
\hline
\end{tabular}

Fonte: Elaboração própria com base na análise das atas e resoluções.

Atuação dos conselhos na decisão e controle sobre a execução dos gastos federais nas ações socioassistenciais (BPC, benefícios eventuais, serviços, programas e projetos)

BPC e benefícios eventuais

Os benefícios socioassistenciais integram a política de assistência social e se dividem em duas modalidades com públicos-alvo específicos: o Benefício de Prestação Continuada da Assistência Social (BPC) e os benefícios eventuais. O BPC consiste em uma importante política de garantia de renda não contributiva e sua regulamentação ocorreu em 1993, com a promulgação da Loas.

Diferente dos serviços socioassistenciais, cuja dinâmica é mais descentralizada, o BPC e também o Programa Bolsa Família, objeto de análise do próximo tópico, concentram decisões e execução no nível nacional de governo. As transferências são diretas do governo federal ao cidadão a partir de critérios definidos por legislação nacional. O BPC é ainda mais centralizado que o Bolsa Família, uma vez que é formulado no âmbito nacional e operado pelo INSS, que é responsável pelo cadastro de beneficiários, concessão do recurso e perícia médica, sem intermediação de estados e municípios (Licio, 2012). Ainda, a regulamentação federal que o normatiza não estabelece nem mesmo competências para o CNAS e, tampouco, para os conselhos subnacionais. Cabe ao CNAS apenas sugerir ao Executivo alterações nos critérios de elegibilidade do BPC.

Os poucos trechos (8) identificados nas atas do CNAS registram discussão sobre 
elevar a renda familiar para um salário mínimo como critério de concessão desse benefício. Na dimensão resultado, não existem resoluções específicas para o BPC, congruente com o que prevê a regulamentação nacional.

A ausência de discussão e resoluções específicas sobre o financiamento do BPC também é verificada nos conselhos subnacionais, com exceção de uma ocorrência de discussão em relação aos recursos destinados à revisão desse benefício, no Ceas MG. Dessa forma, o centralismo fiscal desse benefício não somente concentra no nível nacional as decisões e implementações de suas ações, como também não favorece a participação social institucionalizada.

Em perspectiva mais descentralizada, os benefícios eventuais são regulamentados pela Loas e pelo Decreto Federal no 6.307, de 2007, que não padronizam os valores nem o perfil dos beneficiários. A União regulamenta apenas a caracterização desses benefícios, por meio de decreto, em complemento às diretrizes definidas pelo CNAS. Os conselhos subnacionais devem, portanto, definir critérios e formas para a sua concessão. Sua prestação e seu financiamento são de competência dos municípios e do Distrito Federal, com responsabilidade sobre sua regulamentação e com cofinanciamento pelos estados.

A discussão desses benefícios concentrou-se nos conselhos subnacionais (29 trechos), sendo o Ceas MG o conselho que mais debateu o assunto (15 ocorrências), seguido pelo CMAS BH (7 ocorrências) e pelo Ceas RS ( 6 ocorrências). No CMAS PoA identificou-se apenas um trecho. Destaca-se o caso do Ceas MG, que, em 2010, apresentou em ata a normatização do cofinanciamento estadual desse benefício, por meio do Piso Mineiro de Assistência Social.

Em relação à dimensão resultado, foram identificadas duas resoluções do CNAS que definem regras para os benefícios eventuais. Tais documentos evidenciaram o cumprimento da competência definida pela Loas e o fortalecimento desse conselho pelo centralismo fiscal.

No caso dos conselhos subnacionais, foram identificadas duas resoluções do Ceas MG e uma do CMAS PoA, corroborando a baixa discussão sobre o financiamento desses benefícios identificada na análise das atas. Registraram-se ausência de regulamentação e uma diversidade de critérios para a concessão e custeio dos benefícios eventuais nas IPs subnacionais, principalmente no que tange ao cofinanciamento estadual destes.

As resoluções sobre regras dos benefícios eventuais produzidas pelo CNAS sugerem que o centralismo fiscal fortaleceu a atuação desse conselho, que não apenas definiu critérios e prazos para os entes subnacionais e respectivos conselhos, mas também provocou a regulamentação desses benefícios por decreto federal. Contudo, a ausência de resoluções do CNAS e decretos federais, definindo valores e critérios para a concessão, afetou de modo diferenciado os conselhos subnacionais, que não tiveram parâmetros para definir e controlar o financiamento dos benefícios eventuais. A regulamentação federal limitada a aspectos gerais desses benefícios contribuiu para o fortalecimento da capacidade decisória dos conselhos de Belo Horizonte e de Minas Gerais, enquanto, nos de Porto Alegre 
EDITE DA PENHA CUNHA; ISABELLA LOURENÇO LINS; MÁRCIA MIRANDA SOARES

e do Rio Grande do Sul, verificou-se o não cumprimento das competências em relação a eles.

Quadro 3

Efeitos do centralismo fiscal no subtema Decisão e controle sobre a execução dos gastos nos benefícios eventuais, por conselho (2003-2010)

\begin{tabular}{|c|c|c|c|c|c|}
\hline Pressuposto & Conselho & $\begin{array}{c}\begin{array}{c}\text { Dimensão de } \\
\text { análise }\end{array} \\
\end{array}$ & $\begin{array}{c}\text { Trechos de } \\
\text { confirmação do } \\
\text { pressuposto }\end{array}$ & $\begin{array}{l}\text { Trechos de não } \\
\text { confirmação do } \\
\text { pressuposto }\end{array}$ & $\begin{array}{c}\text { Total de } \\
\text { ocorrências }\end{array}$ \\
\hline \multirow{2}{*}{$\begin{array}{l}\text { Fortalecimento } \\
\text { pelo centralismo } \\
\text { fiscal }\end{array}$} & \multirow{2}{*}{ CNAS } & Funcionamento & 3 & 0 & 3 \\
\hline & & Resultado & 2 & 0 & 2 \\
\hline \multirow{8}{*}{$\begin{array}{l}\text { Constrangimento } \\
\text { pelo centralismo } \\
\text { fiscal }\end{array}$} & CEAS MG & Funcionamento & 0 & 15 & 15 \\
\hline & & Resultado & 0 & 2 & 2 \\
\hline & \multirow[b]{2}{*}{ CEAS RS } & Funcionamento & 0 & 6 & 6 \\
\hline & & Resultado & - & - & - \\
\hline & \multirow{2}{*}{ CMAS BH } & Funcionamento & 0 & 7 & 7 \\
\hline & & Resultado & - & - & - \\
\hline & \multirow{2}{*}{$\begin{array}{c}\text { CMAS } \\
\text { PoA }\end{array}$} & Funcionamento & 0 & 1 & 1 \\
\hline & & Resultado & 0 & 1 & 1 \\
\hline
\end{tabular}

Fonte: Elaboração própria com base na análise das atas e resoluções.

Serviços, programas e projetos

Os serviços são atividades continuadas que visam à melhoria de vida da população e cujas ações, voltadas para as necessidades básicas, observam os objetivos, princípios e diretrizes estabelecidos na Loas (art. 23). Os programas, previstos no artigo 24 da Loas, são ações integradas e complementares com objetivos, tempo e área de abrangência definidos para qualificar, incentivar e melhorar os benefícios e os serviços assistenciais. Os projetos de enfrentamento da pobreza compreendem a instituição de investimento econômico-social nos grupos populares, buscando subsidiar, financeira e tecnicamente, iniciativas que Ihes garantam meios, capacidade produtiva e de gestão para melhoria das condições gerais de subsistência (art. 25, Loas).

Os conselhos devem participar tanto da decisão como do controle da execução dos gastos dessas ações. Em relação à decisão, os conselhos nacional e estaduais devem aprovar critérios de transferência de recursos para os entes subnacionais e disciplinar os procedimentos de transferência e repasse de recursos para as entidades e organizações de assistência social; aos conselhos municipais cabe também definir critérios para o repasse de recursos financeiros às entidades de assistência social situadas no seu âmbito. Em relação ao controle dos gastos, os conselhos têm como competência acompanhar, avaliar e fiscalizar a gestão dos recursos, bem como os ganhos sociais e o desempenho dos serviços, programas e projetos socioassistenciais. 
$\mathrm{Na}$ análise das atas, foi possível identificar e classificar 443 trechos sobre serviços, programas e projetos, sendo esse aspecto o mais discutido ( $51 \%$ ) pelos conselhos, quando comparado a benefícios (5\%), proposta orçamentária (20\%) e prestação de contas (24\%).

A distribuição desses trechos, por conselho, apresenta variações (Quadro 4). A maior incidência de discussões no CMAS PoA pode ser explicada pela periodicidade das reuniões plenárias, que era quinzenal, e pela sua dinâmica de discussão mais intensa.

A maior parte dos trechos do CNAS classificados (113 trechos) sugere que o centralismo fiscal (em seu aspecto jurisdicional) fortaleceu sua capacidade para decidir e controlar a execução dos gastos nas ações socioassistenciais, enquanto o pressuposto de fortalecimento desse conselho não se confirmou em poucos trechos (10), como no caso do PBF.

O CNAS ganhou destaque: na definição dos recursos necessários para custear os serviços socioassistenciais; nas discussões sobre o cofinanciamento para a definição de critérios de partilha dos recursos federais transferidos para os entes subnacionais; em decisões acerca das pactuações realizadas no âmbito da Comissão Intergestores Tripartite $(\mathrm{CIT})^{8}$ em relação às condições de transferência de recursos para estados e municípios; e nas discussões sobre a nova sistemática de financiamento da assistência social.

O efeito do centralismo fiscal no fortalecimento do CNAS, especialmente em sua dimensão de regulamentação do gasto da União com a política de assistência social, também pode ser observado no processo de discussão conduzido por esse conselho para aprovação dos novos critérios de partilha dos recursos orçamentários do FNAS com os fundos subnacionais, mediante o cumprimento de regulamentações federais.

Em relação ao controle do gasto, o CNAS acompanhou o repasse de recursos federais para a rede de serviços de ação continuada (SAC), os convênios para os programas e projetos de combate ao abuso e exploração sexual, o Agente Jovem e a implantação dos equipamentos públicos em todo o território nacional, assim como para as pactuações da CIT para a transferência de recursos do FNAS aos fundos municipais e as discussões sobre o cofinanciamento.

No âmbito do governo federal, a iniciativa de enfrentamento à pobreza com maior destaque no período analisado foi o PBF, que tem sua formulação e execução centralizados na União (Almeida, 2005; Bichir, 2011; Licio, 2012). Os estados e municípios atuam apenas de forma complementar na execução. Aos primeiros cabe a participação na gestão do PBF, com a função de apoiar os municípios com suporte tecnológico e capacitação. Enquanto os municípios atuam, em especial, na alimentação do cadastro e no acompanhamento das famílias quanto ao cumprimento das condicionalidades

\footnotetext{
8 A Comissão Intergestores Tripartite (CIT) de Assistência Social foi criada pela NOB/02, aprovada pela Resolução no 207/CNAS de 16 de dezembro de 1998, como arena federativa de deliberação da política de assistência social, sendo composta por gestores das três esferas de governo e do DF. É responsável pela negociação de aspectos operacionais da gestão nacional do sistema de assistência social.
} 
do programa (Cadúnico). Dessa forma, esses entes participam na sua implementação quase como "agentes administrativos do governo central" (Almeida, 2005).

Apesar de ter suas decisões predominantemente tomadas no nível central, na regulamentação desse programa não existe previsão de atribuições para o CNAS em relação a aspectos de seu financiamento. Assim como no BPC, a centralização do PBF diz respeito ao Executivo Federal, predominantemente, com pouco espaço para participação social.

Em relação à dimensão resultado, foram identificadas 14 resoluções do CNAS que expressavam a sua capacidade de atuação na decisão sobre o financiamento. Estas consistiam em propostas que estabeleceram normas para a celebração de convênios, recursos para estruturação de equipamentos públicos (Cras e Creas), além da pactuação de critérios de expansão do gasto em serviços e a definição de critérios de partilha e pisos para o cofinanciamento federal.

Em geral, a regulamentação federal e a crescente alocação de recursos na política de assistência social fortaleceram o CNAS para atuar seja na definição de critérios de partilha e de transferência de recursos, seja na nova sistemática de financiamento, seja no controle da execução dos gastos.

O pressuposto de que a capacidade dos conselhos subnacionais é constrangida pelo centralismo fiscal foi confirmado em 320 trechos de atas, sendo 48 (15\%) no Ceas MG, 22 (7\%) no Ceas RS, 83 (26\%) no CMAS BH e 167 (52\%) no CMAS PoA (Quadro 3). Esses dados evidenciaram que aspectos e/ou condições definidas pelo centralismo fiscal formataram as discussões dos conselhos subnacionais relacionadas à decisão e ao controle da execução dos gastos com os serviços, programas e projetos socioassistenciais.

Nas atas do Ceas MG, 48 trechos expressaram o constrangimento causado pelo centralismo, por exemplo, quando esse conselho controla os pagamentos dos convênios, a implantação e adequação dos Cras e Creas cofinanciados pelo FNAS, assim como as mudanças necessárias das ações cofinanciadas com o piso básico de transição, cumprindo os critérios estabelecidos pelas regulamentações federais.

As evidências encontradas no caso do Ceas RS (22 trechos) sugerem que sua capacidade de decidir e controlar a execução dos gastos foi constrangida pelo centralismo fiscal. Assim como o Ceas de Minas, essa IP foi constrangida pelo gasto da União com a política, uma vez que a decisão sobre os critérios de partilha dos recursos ficou limitada àqueles referentes ao seu âmbito, e, no caso dos recursos federais, deliberou apenas em relação à pactuação e manutenção da planilha de recursos do Ministério da Assistência Social, substituído pelo MDS, mantendo, em 2004 e 2005, os mesmos critérios de partilha de 2003 para a rede SAC.

Nos casos dos conselhos municipais, foram encontrados mais trechos (250) quando comparados aos conselhos estaduais, que sugerem a confirmação do pressuposto de constrangimento pelo centralismo fiscal. No CMAS BH, identificaram-se 83 trechos, sendo que o constrangimento apresenta-se de forma mais frequente quando o conselho aprova, 
com base em parâmetros definidos no âmbito federal, a celebração, a renovação, o cancelamento e/ou a suspensão dos convênios cofinanciados pelo FNAS, além dos reajustes e/ou ampliação de metas para entidades conveniadas; e a prorrogação de vigência e a apreciação de convênios, assim como o reordenamento da rede de serviços cofinanciada com o piso de transição, de acordo com as novas modalidades da política regulamentada no âmbito federal.

O controle da execução do gasto nessas ações apresentou-se constante, especialmente no que se refere aos pagamentos de convênios e atrasos nos repasses para as entidades, além de proposições em relação ao estudo dos custos dos serviços da rede. Assim, a regulamentação federal, ao mesmo tempo em que determina a necessidade desse controle pelos conselhos para a continuidade do recebimento dos recursos, também delimita os parâmetros e critérios para que isso ocorra.

No CMAS PoA, identificou-se que o centralismo fiscal constrange a capacidade desse conselho (167 trechos), sendo mais frequentes as discussões em torno da adequação dos serviços cofinanciados para assegurar a continuidade e para ampliar o recebimento dos recursos do FNAS.

O centralismo fiscal se apresenta como fator de constrangimento no CMAS PoA na medida em que formatou as discussões relacionadas à renovação, ao cancelamento ou à suspensão dos convênios cofinanciados com recursos federais; à aprovação dos reajustes e/ou à ampliação de metas; aos recursos para instalação dos Cras e Creas, assim como ao controle dos gastos dos recursos oriundos do FNAS. Quanto às discussões em relação ao Bolsa Família, identificaram-se situações que também denotaram o constrangimento desse conselho, uma vez que são definidas condições de repasse de recursos, as quais este não consegue alterar.

Os conselhos subnacionais analisados produziram 889 resoluções relacionadas à decisão e ao controle da execução dos gastos com serviços, programas e projetos de assistência social. Essa produção apresentou variação por conselho, sendo as resoluções municipais as que apresentaram o maior número. O CMAS PoA produziu 490 resoluções (55\%), enquanto o CMAS BH, 230 (26\%). Nas IPs estaduais, o subtema apareceu em 50 (6\%) e $119(13 \%)$ resoluções do Ceas MG e Ceas RS, respectivamente.

O pressuposto de constrangimento dos conselhos subnacionais pelo centralismo fiscal foi confirmado, na medida em que se identificou nos conteúdos das resoluções a atuação desses conselhos na aprovação de regras próprias para conveniamento e no acompanhamento da execução dos gastos com serviços, programas e projetos cofinanciados com recursos federais, observando-se os parâmetros estabelecidos pelas regulamentações federais.

Não foram encontrados resultados produzidos pelas IPs em relação ao Bolsa Família, à exceção do CMAS PoA, em que se observaram três resoluções sobre a aprovação da prestação de contas dos recursos do Índice de Gestão Descentralizada (IGD) e duas relativas à aprovação da liberação de recursos para implantação e investimento no 
programa.

Conclui-se que a atuação do CNAS na decisão e no controle da execução dos gastos relativos aos benefícios, serviços, programas e projetos de assistência social, com exceção do BPC e PBF, foi fortalecida pelo centralismo fiscal. No caso dos conselhos subnacionais, também foi confirmado o pressuposto de que o centralismo constrange sua atuação quanto à decisão e controle sobre a execução dos gastos com as ações da política de assistência social, com destaque para os benefícios eventuais, e de que a ausência do centralismo fiscal contribui tanto para o fortalecimento da capacidade decisória dos conselhos subnacionais, como nos casos de Belo Horizonte e Minas Gerais, quanto para o não cumprimento das competências destas em relação a esse tipo de benefício, como ocorrido em Porto Alegre e no Rio Grande do Sul.

Enfim, o constrangimento do centralismo fiscal foi identificado na regulamentação dos aspectos e condições para a decisão e controle da aplicação dos recursos federais pelas IPs subnacionais. A dependência de regras nacionais para o recebimento de recursos nacionais pelos entes subnacionais, o que contribui para o custeio das ações socioassistenciais, tendo destaque os repasses fundo a fundo, faz com que as respectivas IPs busquem adequar-se aos parâmetros e condicionalidades estabelecidos no nível central de governo.

A adesão dos municípios às transferências realizadas no âmbito do FNAS para o cofinanciamento da assistência social encontra-se expressa nos dados da Munic (2009), os quais informam que $87,3 \%$ dos municípios brasileiros declararam receber cofinanciamento federal e/ou estadual para a função de assistência social, sendo que essas proporções atingiram $100 \%$ no caso dos municípios de grande e médio portes.

Quadro 4

Efeitos do centralismo fiscal no subtema Decisão e controle sobre a execução dos gastos nos serviços socioassistenciais, por conselho (2003-2010)

\begin{tabular}{|c|c|c|c|c|c|}
\hline Pressuposto & Conselho & $\begin{array}{c}\text { Dimensão de } \\
\text { análise }\end{array}$ & $\begin{array}{l}\text { Trechos de } \\
\text { confirmação do } \\
\text { pressuposto }\end{array}$ & $\begin{array}{c}\text { Trechos de não } \\
\text { confirmação do } \\
\text { pressuposto }\end{array}$ & $\begin{array}{c}\text { Total de } \\
\text { ocorrências }\end{array}$ \\
\hline \multirow{2}{*}{$\begin{array}{l}\text { Fortalecimento } \\
\text { pelo centralismo } \\
\text { fiscal }\end{array}$} & \multirow{2}{*}{ CNAS } & Funcionamento & 113 & 10 & 123 \\
\hline & & Resultado & 14 & 0 & 14 \\
\hline \multirow{8}{*}{$\begin{array}{l}\text { Constrangimento } \\
\text { pelo centralismo } \\
\text { fiscal }\end{array}$} & \multirow{2}{*}{ Ceas MG } & Funcionamento & 48 & 0 & 48 \\
\hline & & Resultado & 50 & 0 & 50 \\
\hline & \multirow{2}{*}{ Ceas RS } & Funcionamento & 22 & 0 & 22 \\
\hline & & Resultado & 119 & 0 & 119 \\
\hline & \multirow{2}{*}{ CMAS BH } & Funcionamento & 83 & 0 & 83 \\
\hline & & Resultado & 230 & 0 & 230 \\
\hline & \multirow{2}{*}{$\begin{array}{c}\text { CMAS } \\
\text { POA }\end{array}$} & Funcionamento & 167 & 0 & 167 \\
\hline & & Resultado & 490 & 0 & 490 \\
\hline
\end{tabular}

Fonte: Elaboração própria, com base na análise das atas e resoluções. 
Atuação dos conselhos no controle da prestação de contas dos recursos do FNAS

Em relação ao controle do financiamento da política de assistência social, destacase a competência dos conselhos de aprovar a prestação de contas dos recursos financeiros repassados pelo FNAS. A Loas estabelece apenas para o CNAS a competência de divulgar no Diário Oficial todas as suas decisões e os pareceres em relação à utilização dos recursos do FNAS. No Manual de Orientações de Convênios e em portarias do MDS tem-se a definição das atribuições dos conselhos em relação ao controle sobre as prestações de contas, como aprovação do relatório de cumprimento do objeto de convênios, verificação do cumprimento das metas físicas e financeiras do Plano de Ação, recomendação de devolução de recursos sobrantes repassados pelo FNAS e avaliação e cadastro do parecer do conselho competente sobre a prestação de contas e reprogramação de saldo.

Identificaram-se e classificaram-se nas atas 211 trechos relacionados ao subtema Prestação de contas de recursos do FNAS. A distribuição desses trechos apresentou variações (Quadro 5). No CNAS, de 40 trechos, 38 (95\%) expressavam o fortalecimento da sua atuação pelo centralismo e dois ( $5 \%)$ tratavam da dificuldade de realizarem suas atribuições devido ao atraso na entrega da prestação de contas.

Em relação ao resultado do CNAS, identificaram-se 28 resoluções de aprovação de prestação de contas, sendo apenas uma aprovada com ressalva, que solicitava a apresentação trimestral e anual de dados da execução física e a nota explicativa sobre os resultados alcançados, e outra com recomendação para a inclusão nos relatórios das metas físicas executadas e de nota explicativa com a identificação de ações e projetos por unidade da Federação.

As demais resoluções apresentaram-se detalhadas, atendendo, assim, a demandas do CNAS quanto à necessidade de esclarecimentos e de transparência em relação à utilização dos recursos do FNAS.

No caso dos conselhos subnacionais, a centralização fiscal tendeu a constranger suas atuações no controle da aplicação dos recursos federais (171 trechos de atas). O Ceas MG registrou a maior frequência de trechos que evidenciam esse constrangimento, 76 (45\%), seguido do CMAS BH e CMAS PoA, com 36 (21\%) e 35 (20\%), respectivamente. No Ceas RS, entre os 24 trechos (14\%) que representam constrangimento, também se verificou a ausência de prestação de contas pelo gestor estadual.

A regulamentação da operacionalização do Suasweb, sistema nacional que operacionalizava a prestação de contas dos recursos repassados pelo FNAS, tendeu a impor constrangimentos aos conselhos subnacionais. Estes podiam ser temporais, como o cumprimento dos prazos estabelecidos pelo MDS, e/ou a aplicação de sanções aos governos subnacionais, como a suspensão e até mesmo a devolução dos recursos federais repassados.

No CMAS PoA, também se identificou menção à sanção de suspensão dos recursos 
federais para o município, caso o conselho não emitisse parecer sobre a prestação de contas. Em diversas situações, o conselho não concordou com a prestação de contas; contudo, para não prejudicar o município no recebimento desses recursos, acabou aprovando-a com ressalvas, denotando um dilema no controle dos recursos executados na política.

O cumprimento da competência dos conselhos subnacionais de apreciar as prestações de contas depende da apresentação regular destas pelos gestores. Se, por um lado, o centralismo fiscal pode impor constrangimentos para o controle dos recursos federais pelos conselhos, por outro, os gestores subnacionais também podem criar determinadas condições que afetam a atuação destes, como o atraso na entrega, a falta de informações precisas e completas e o não envio das prestações de contas.

A despeito do contexto político no qual os conselhos subnacionais estavam inseridos, os gestores da política, nos casos analisados, tenderam a acatar as suas demandas em relação aos esclarecimentos acerca das prestações de contas para sua aprovação e a formulação de instrumentos de apoio para sua análise. A necessidade do cumprimento das regras para o recebimento de recursos federais denotou que 0 centralismo fiscal também pode validar o papel de controle dos conselhos subnacionais em relação às transferências intergovernamentais no nível central.

O resultado produzido pelos conselhos subnacionais em relação à Prestação de contas dos recursos federais repassados para os respectivos fundos subnacionais encontrase expresso em 98 resoluções, com variações por conselho. O CMAS BH e, na sequência, o Ceas MG foram os conselhos em que se identificou o maior número de resoluções, com, respectivamente, $33(34 \%)$ e 30 (31\%). O CMAS PoA apresentou 18 (18\%) resoluções nesse subtema, seguido pelo Ceas RS, com 17 (17\%).

O maior número de resoluções expedidas pelos conselhos subnacionais, com exceção do Ceas RS e do CMAS PoA, sugere o cumprimento do seu papel de controle. Comparando-se as resoluções relativas a decisões acerca da proposta orçamentária e da execução dos recursos, observa-se que os conselhos subnacionais controlam mais do que decidem sobre o financiamento da assistência social.

As ressalvas e/ou observações identificadas expressaram as discordâncias dos conselhos em relação às prestações de contas apresentadas, assim como registraram recomendações para que os gestores ajustassem procedimentos e garantissem maior transparência aos atos de aplicação dos recursos. Contudo, o receio das sanções de suspensão ou corte dos recursos federais, dos quais os entes subnacionais dependem para execução da política, tendeu a levar os conselhos subnacionais, mesmo discordando das prestações apresentadas ou não as tendo analisado por falta de tempo, a aprová-las.

As ressalvas sugeriram a incidência do constrangimento das regulamentações federais e do gasto da União sobre o resultado produzido por esses conselhos, como no caso do CMAS PoA, que, para não prejudicar o município no recebimento de recursos federais, respondeu aos questionamentos feitos pelo órgão gestor federal e reviu sua 
decisão de reprovar uma prestação de contas.

No subtema Prestação de contas, o centralismo fiscal, tanto no aspecto da regulamentação quanto no gasto da União com a política, causou constrangimentos para o funcionamento dos conselhos subnacionais, assim como fortaleceu o CNAS. O condicionamento do recebimento de recursos federais pelos entes subnacionais à existência de parecer sobre a prestação de contas pelos conselhos subnacionais e a delimitação de parâmetros e mecanismos para o processamento dessas prestações incidiram positivamente na relação dos conselhos com os respectivos gestores, que tenderam a cumprir seu papel como forma de assegurar os recursos para a política de assistência social. Sendo assim, apesar de constrangimento na agenda dos conselhos subnacionais, o centralismo fiscal também teve um efeito de validar o papel das IPs subnacionais no controle do financiamento da assistência social perante os gestores estaduais e municipais.

\section{Quadro 5 \\ Efeitos do centralismo fiscal no subtema Prestação de contas do FNAS, por conselho (2003-2010)}

\begin{tabular}{|c|c|c|c|c|c|}
\hline Pressuposto & Conselho & $\begin{array}{c}\text { Dimensão de } \\
\text { análise }\end{array}$ & $\begin{array}{l}\text { Trechos de } \\
\text { confirmação do } \\
\text { pressuposto }\end{array}$ & $\begin{array}{l}\text { Trechos de não } \\
\text { confirmação do } \\
\text { pressuposto }\end{array}$ & $\begin{array}{c}\text { Total de } \\
\text { ocorrências }\end{array}$ \\
\hline \multirow{2}{*}{$\begin{array}{l}\text { Fortalecimento } \\
\text { pelo centralismo } \\
\text { fiscal }\end{array}$} & \multirow{2}{*}{ CNAS } & Funcionamento & 38 & 2 & 40 \\
\hline & & Resultado & 28 & 0 & 28 \\
\hline \multirow{8}{*}{$\begin{array}{l}\text { Constrangimento } \\
\text { pelo centralismo } \\
\text { fiscal }\end{array}$} & \multirow{2}{*}{ Ceas MG } & Funcionamento & 76 & 0 & 76 \\
\hline & & Resultado & 30 & 0 & 30 \\
\hline & \multirow{2}{*}{ Ceas RS } & Funcionamento & 24 & 0 & 24 \\
\hline & & Resultado & 17 & 0 & 17 \\
\hline & \multirow{2}{*}{ CMAS BH } & Funcionamento & 36 & 0 & 36 \\
\hline & & Resultado & 33 & 0 & 33 \\
\hline & \multirow{2}{*}{$\begin{array}{l}\text { CMAS } \\
\text { POA }\end{array}$} & Funcionamento & 35 & 0 & 35 \\
\hline & & Resultado & 18 & 0 & 18 \\
\hline
\end{tabular}

Fonte: Elaboração própria com base na análise das atas e resoluções.

\section{Conclusões}

A assistência social destaca-se como uma política marcada pela centralização fiscal nacional no período que se seguiu à $\mathrm{CF} / 88$. A União, com destaque para o Executivo nacional, teve papel relevante na regulamentação e execução dos gastos da política nacional de assistência social no período de 2003 a 2010, cabendo ao MDS a coordenação e execução de ações necessárias à sua implementação em todo o território nacional. Essa 
situação caracteriza, conforme Arretche (2004, 2010), um quadro em que o nível central é o principal regulador da política pública e a autonomia decisória das unidades subnacionais é afetada. Neste artigo, buscou-se verificar se a dinâmica centralizadora dessa política também incidiu no funcionamento e no resultado produzidos pelos conselhos de assistência social.

Para isso, utilizou-se de análise documental, confrontando a legislação federal com trechos de atas e resoluções do conselho nacional, de dois conselhos estaduais e dois municipais. Esperava-se que o centralismo fiscal fortalecesse o CNAS e tivesse efeito inverso nas IPs subnacionais no que diz respeito à sua capacidade de decidir e controlar o financiamento da assistência social.

Nos cinco subtemas do Financiamento analisados, os efeitos encontrados foram na direção esperada, mas não para todos os casos, nem com a mesma intensidade. Para o CNAS, pode-se confirmar o pressuposto de fortalecimento da capacidade desse conselho, pelo centralismo fiscal, em quase todos os subtemas analisados, exceto nos casos do BPC e PBF, nos quais, apesar da centralização federal nos gastos e na regulamentação desse benefício e desse programa, o CNAS não teve participação na definição e na regulamentação do seu financiamento.

Nos casos dos conselhos subnacionais, tem-se também, com exceção nos benefícios eventuais, a confirmação do pressuposto de que o centralismo fiscal constrangeu a capacidade de atuação desses conselhos. Os resultados de constrangimentos encontrados nas atas e resoluções dos entes subnacionais estão associados, principalmente, à dependência destes de regulamentação nacional do financiamento da política, inclusive na definição de recursos federais para a implementação da política. Assim, os conselhos buscaram adequar-se aos parâmetros e condicionalidades estabelecidos pela regulamentação federal para terem acesso aos recursos nacionais, com destaque para aqueles do FNAS.

No caso dos benefícios eventuais, a ausência do centralismo fiscal teve efeitos diferenciados, tanto positivos quanto negativos. A centralização da regulamentação federal limitada a aspectos gerais desses benefícios contribuiu para o fortalecimento da capacidade decisória dos conselhos subnacionais, que definiram questões relacionadas a financiamento e regras de destinação dos benefícios. Por outro lado, essa ausência também levou ao não cumprimento de competências em relação a estes, por exemplo, não definição de cofinanciamento estadual para esses benefícios.

Ainda, nos subtemas Orçamento e Serviços, programas e projetos, foram encontrados outros fatores não relacionados ao centralismo fiscal que também incidiram sobre a capacidade de atuação dos conselhos. No CNAS, em relação ao Orçamento, identificaram-se as regras gerais do processo orçamentário, como os prazos para apresentação das propostas de lei e a falta de conhecimento técnico sobre o orçamento; nos Serviços, programas e projetos, a exigência de CND para a efetivação de transferência de recursos entre os entes federados, o prazo de aprovação do orçamento, entre outros 
constrangimentos que também afetaram a atuação desse conselho. Nos subnacionais, identificaram-se fatores como a relação com o gestor do governo estadual ou municipal, a autonomia dos entes subnacionais para definir as fontes e as formas de gestão de recursos próprios, como a Loteria Mineira, a Lei da Solidariedade no RS, o Orçamento Participativo (OP) em PoA e as emendas parlamentares. No caso do Ceas RS, por exemplo, projetos socioassistenciais financiados pela Lei da Solidariedade não se orientam pelas diretrizes do Suas e representam mais da metade das resoluções produzidas por esse conselho. Essas outras variáveis identificadas, que fogem ao escopo mais específico do trabalho, apontam para aspectos diferenciadores do funcionamento e da produção de resultado pelas IPs subnacionais que podem ser explorados em outros trabalhos.

A conclusão geral, a partir do estudo de cinco casos, é que o centralismo do governo federal na política de assistência social, no qual o financiamento tem papel de destaque, foi importante para induzir as ações nos níveis subnacionais, isto é, promover o alinhamento, principalmente dos governos locais, às prioridades da agenda federal (Arretche, 2012), algo que alcançou também os conselhos dessa política. Com isso, em um contexto político favorável, houve, em pouco tempo, como apontam dados da Munic (2009), uma evolução muito positiva na universalização e na equidade dessa política em todo o território nacional, com destaque para os municípios. Contudo, reconhece-se que isso afetou a autonomia política decisória das unidades subnacionais, com reflexos diretos nos conselhos de assistência social em sua capacidade para decidir e controlar o financiamento, conforme identificado neste artigo.

O centralismo fiscal teve efeito positivo na IP nacional e, em algumas situações, também sobre as IPs subnacionais, por exemplo, ao validar o papel destas perante os gestores locais e ao estabelecer a vinculação do recebimento de recursos federais aos pareceres emitidos por elas. Contudo, esse efeito tendeu a induzir os conselhos a atuarem como instituição de controle da União sobre o financiamento federal para implementação da política pelos entes subnacionais. Em relação às IPs subnacionais, esse é um aspecto que merece reflexão: qual deve ser o papel dos conselhos na formulação e implementação das políticas públicas?

A indução federal, no aspecto do financiamento, leva os conselhos de estados e municípios a uma atuação mais reativa que propositiva em resposta às demandas provenientes do Executivo federal, conforme destacam Almeida e Tatagiba (2012). Contudo, este artigo evidencia que o CNAS, diferentemente, foi fortalecido pelo centralismo fiscal e teve uma atuação propositiva em relação a aspectos da decisão e controle do financiamento da assistência social. Os achados, decorrentes deste estudo exploratório e em profundidade de alguns casos, podem constituir-se em hipóteses a guiar pesquisas futuras envolvendo outros conselhos de assistência social, outras periodicidades ou, ainda, outras IPs de políticas públicas.

Importante também destacar que o centralismo fiscal, componente da polity, pode favorecer uma determinada política pública (policy), como foi o caso apresentado aqui da 
assistência social no período de 2003 a 2010, mas também pode ter efeitos neutros ou negativos, a depender do contexto político do governo federal (politics). No período analisado, o governo federal colocou a assistência social como uma agenda prioritária, o que reverberou positivamente na regulamentação e no aumento nos gastos com a política. Tal fato também teve efeito positivo no aumento do controle social do financiamento federal. Contudo, a alteração dessa dinâmica política pode trazer efeitos diferenciados, inclusive na direção inversa, com constrangimento na atuação do conselho nacional. Isso remete à necessidade de novos estudos que contemplem a variável dinâmica política do governo central. Um governo com um projeto político que não tenha um viés participativo pode criar novas regras de financiamento da política, por exemplo, estabelecer novas condicionalidades para aprovação de prestação de contas sem a participação dos conselhos. O centralismo fiscal pode, dessa forma, ser usado pelo governo central para afetar negativamente o funcionamento das IPs.

Espera-se, com este artigo, contribuir para o avanço da compreensão sobre o potencial da teoria do federalismo nas agendas de pesquisas que tenham por objeto a participação institucionalizada no processo decisório e no controle das políticas públicas. 0 aspecto principal a ser destacado é que os resultados apresentados apontam para a importância do federalismo brasileiro na conformação da política de assistência social e de seus conselhos. Contudo, estudos futuros de outros casos são necessários para corroborar os resultados deste artigo e/ou incluir novas perspectivas de análise.

\section{Referências bibliográficas}

ABRUCIO, F. L. "A coordenação federativa no Brasil: a experiência do período FHC e os desafios do governo Lula". Revista de Sociologia e Política, n² 24, p. 41-67, 2005.

. Para além da descentralização: os desafios da coordenação federativa no Brasil. In: FLEURY, S. (org.). Democracia, descentralização e desenvolvimento: Brasil e Espanha. Rio de Janeiro: Editora FGV, 2006.

- A dinâmica federativa da educação brasileira: diagnóstico e propostas de aperfeiçoamento. In: Oliveira, R. P.; SANTANA, W. (orgs.). Educação e federalismo no Brasil: combater as desigualdades, garantir a diversidade. Brasília, DF: Unesco, 2010.

AlmeidA, C. C.; TATAgiBA, L. "Os conselhos gestores sob o crivo da política: balanços e perspectivas". Serviço Social \& Sociedade, São Paulo, no 109, mar. 2012.

ALMEIDA, D. C. "Participação nos conselhos gestores: uma ponte entre teoria e prática deliberativas". In: $6^{\circ}$ Encontro da Associação Brasileira de Ciência Política - ABCP. Unicamp, Campinas, SP, set. 2008.

ALmeida, M. H. T. "Recentralizando a federação?". Revista de Sociologia e Política, no 24, p. 29-40, 2005.

ARretche, M. T. "Políticas sociais no Brasil: descentralização em um Estado federativo". Revista Brasileira de Ciências Sociais, vol. 14, no 40, p. 111-141, 1999. 
ARretche, M. T. Estado federativo e políticas sociais: determinantes da descentralização. Rio de Janeiro/São Paulo: Editora Revan/Fapesp, 2000.

."Federalismo e relações intergovernamentais no Brasil: a reforma de programas sociais". Revista Dados, Rio de Janeiro, vol. 45, n 3, p. 431-458, 2002.

. "Federalismo e políticas sociais no Brasil: problemas de coordenação e autonomia". São Paulo em Perspectiva, São Paulo, vol. 18, no 2, p. 17-26, 2004.

. Federalismo e políticas sociais no Brasil: problemas de coordenação e autonomia. In: Saravia, E.; Ferrarezi, E. (orgs.). Políticas públicas: coletânea. Brasília: Enap, 2006.

. "Continuidades e descontinuidades da federação brasileira: de como 1988 facilitou 1995". Dados, Rio de Janeiro, vol. 52, no 2, p. 377-423, 2009.

. "Federalismo e igualdade territorial: uma contradição em termos?". Revista Dados, Rio

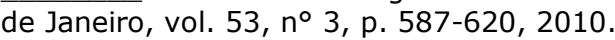

. Democracia, federalismo e centralização no Brasil. Rio de Janeiro: Fiocruz/FGV, 2012.

AVRITZER, L. "Instituições participativas e desenho institucional: algumas considerações sobre a variação da participação no Brasil democrático". Opinião Pública, Campinas, vol. 14, nº 1, jun. 2008.

Beach, D.; Pedersen, R. B. Process-tracing methods: foundations and guidelines. Michigan: Michigan University Press, 2013.

BENNETT, A. Case study methods: design, use, and comparative advantages. In: SPRINZ, D. F.; WolinSKY-NAHMIAS, Y. (eds.). Models, numbers, and cases: methods for studying international relations. Ann Arbor: University of Michigan, 2004.

BICHIR, R. M. "Mecanismos federais de coordenação de políticas sociais e capacidades institucionais locais: o caso do Programa Bolsa Família". Tese de Doutorado, Instituto de Estudos Sociais e Políticos (Iesp), Universidade do Estado do Rio de Janeiro, Rio de Janeiro, 2011.

BlATteR, J.; BLUme, T. "Beyond the co-variational template: alternative directions in case study methodology". In: $4^{\text {th }}$ General Conference of the European Consortium for Political Research. Essex (UK): University of Essex, 2007.

CASTRO, J., et al. "Gasto social e política macroeconômica: trajetórias e tensões no período 19952005". Texto para Discussão no 1324. Brasília: Ipea, 2008.

CASTRO, J., et al. Gasto social federal: prioridade macroeconômica no período 1995-2010. Nota técnica no 9. Brasília: Ipea, 2012.

CORTES, S. M. Instituições participativas e acesso a serviços públicos nos municípios brasileiros. In: PIRES, R. R. C. (org.). Efetividade das instituições participativas no Brasil: estratégias de avaliação. Brasília: Ipea, 2011.

CostA, B. L.; PALOTTI, P. L. "Relações intergovernamentais e descentralização: uma análise da implementação do Suas em Minas Gerais". Revista de Sociologia e Política, vol. 19, p. 211-235, 2011.

CUNHA, E. S. A efetividade deliberativa dos conselhos municipais de saúde e de criança e adolescente no Nordeste. In: Avritzer, L. (org.). A participação social no Nordeste. Belo Horizonte: UFMG, p. 135-162, 2007.

CunHA, E. S., et al. Uma estratégia multidimensional de avaliação dos conselhos de políticas: 
EDITE DA PENHA CUNHA; ISABELLA LOURENÇO LINS; MÁRCIA MIRANDA SOARES

dinâmica deliberativa, desenho institucional e fatores exógenos. In: PIRES, R. R. C. (org.). Efetividade das instituições participativas no Brasil: estratégias de avaliação. Brasília: Ipea, 2011.

CUNHA, E. P. "Federalismo e instituições participativas: os conselhos de assistência social (20032010)". Tese de Doutorado em Ciência Política. Faculdade de Filosofia e Ciências Humanas, Universidade Federal de Minas Gerais, Belo Horizonte, 2018.

DRAIBE, S. M. As políticas sociais brasileiras: diagnósticos e perspectivas de políticas públicas. In: Para a década de 90: prioridades e perspectivas de políticas públicas. Brasília: Ipea/Iplan, 1990.

FARIA, C. F.; CUNHA, E. S. M. "Formação de agenda na política de assistência social: o papel das conferências como um sistema integrado de participação e deliberação". Revista Democracia e Participação. Secretaria Geral da Presidência da República, vol. 1, no 1, 2014.

HALL, P. A.; TAYLOR, R. C. "As três versões do neoinstitucionalismo". Revista Lua Nova, no 58, p. 193-223, 2003.

Lavalle, A. G.; Barone, L. Conselhos, associações e desigualdade. In: ArRetche, M. (org.). Trajetórias das desigualdades: como o Brasil mudou nos últimos cinquenta anos. São Paulo: Centro de Estudos da Metrópole/Editora Unesp, 2015.

Lavalle, A. G.; Voigt, J.; Serafim, L. "O que fazem os conselhos e quando o fazem? Padrões decisórios e o debate dos efeitos das instituições participativas". Dados, vol. 59, no 3, p. 609-650, 2016.

Licio, E. C. "Para além da recentralização: os caminhos da coordenação federativa do Programa Bolsa Família (2003-2010)". Tese de Doutorado, Instituto de Ciências Humanas, Departamento de Serviço Social, Universidade de Brasília, Brasília, 2012.

LIMONGI, F. O Poder Executivo na Constituição de 1988. In: OlIVEN, R. G.; RIDENTI, M.; BRANDÃO, G. M. (orgs.). A Constituição de 1988 na vida brasileira. São Paulo: Aderaldo \& Rothschild/Anpocs, 2008.

MesquiTA, A. ; MARTINS, R.; CRUZ, T. "Cofinanciamento e responsabilidade federativa na política de assistência social". Texto para Discussão nº 1724. Rio de Janeiro: Ipea, 2012.

MunIC - Pesquisa de Informações Básicas Municipais. IBGE, Ministério do Planejamento, Orçamento e Gestão. Coordenação de População e Indicadores Sociais. Perfil dos Municípios Brasileiros. Suplemento de Assistência Social. Brasil, 2009.

PIERSON, P. "Fragmented welfare states: federal institutions and the development of social policies". Governance: An International Journal of Policy and Administration, vol. 8, no 4, p. 449-478, 1995.

PIRES, R. R., et al. Em busca de uma síntese: ambições comuns e abordagens diversificadas na avaliação da efetividade das instituições participativas. In: PIRES, R. R. C. (org.). Efetividade das instituições participativas no Brasil: estratégias de avaliação. Brasília: Ipea, 2011.

RODDEN, J. "Federalismo e descentralização em perspectiva comparada: sobre significados e medidas". Revista de Sociologia e Política, n 24, p. 9-27, jun. 2005.

SÁTYRo, N. G.; CUNHA, E. "A entrada da política de assistência social na agenda decisória brasileira: o papel das leis e o papel do presidente". In: $35^{\circ}$ Encontro Anual da Anpocs GT029 - Políticas Públicas, Caxambu, 2011.

SEAWRIGHT, J.; GERRING, J. "Case selection techniques in case study research: a menu of qualitative and quantitative options". Political Research Quarterly, vol. 61, n², 2008.

SoARes, M. M.; MACHADO, J. A. "Federalismo e políticas sociais no Brasil e na Argentina". In: 10 
FEDERALISMO E CONSELHOS DE ASSISTÊNCIA SOCIAL: UMA ANÁLISE A PARTIR DO FINANCIAMENTO

Encontro da Associação Brasileira de Ciência Política, ABCP, Belo Horizonte, 2016.

SouzA, C. "Federalismo, desenho constitucional e instituições federativas no Brasil pós-1988". Revista Sociologia e Política, no 24, 2005.

TATAGIBA, L. Os conselhos gestores e a democratização das políticas públicas no Brasil. In: DAGniNo, E. (org.). Sociedade civil e espaços públicos no Brasil. São Paulo: Paz e Terra, 2002.

WAMPLER, B. Instituições participativas como "enxertos" na estrutura do Estado: a importância de contextos, atores e suas estratégias. In: PIRES, R. R. C. (org.). Efetividade das instituições participativas no Brasil: estratégias de avaliação. Brasília, Ipea, 2011.

\section{Anexo único}

\section{Codificação dos conteúdos das atas e resoluções}

Os conteúdos das atas e resoluções dos conselhos, relacionados ao tema Financiamento, foram classificados em subtemas definidos a partir da política de assistência social e do conjunto de regulamentações federais: Orçamento, Benefício de Prestação Continuada, Benefícios eventuais, Serviços, programas e projetos e Prestação de contas.

No subtema Orçamento, foram classificados trechos relacionados à discussão da proposta anual de orçamento elaborada pelo Poder Executivo na área da assistência social; da proposta orçamentária dos recursos alocados nos respectivos fundos; da participação do conselho na elaboração e aprovação do PPA, da LDO e da LOA; da articulação com o Legislativo nas fases de elaboração do orçamento e de sua implementação; e da demanda por vinculação de percentual obrigatório para investimento na política de assistência social.

Quanto às ações socioassistenciais, classificou-se, inicialmente, o BPC, que corresponde a trechos relacionados à discussão sobre o financiamento desse benefício, como mudança nos critérios de acesso, os quais implicam alterações em seu custeio. O subtema Benefícios eventuais diz respeito às discussões sobre sua regulamentação, ao estabelecimento de critérios para definição de público-alvo, ao valor e à fonte de custeio, assim como à necessidade do cofinanciamento estadual. Em relação ao subtema Serviços, programas e projetos, foram classificados trechos relacionados a remanejamento de per capita dos serviços de ação continuada, recursos e metas; transferência de recursos e saldos remanescentes de uma entidade para outra; emendas parlamentares; questões relacionadas aos convênios, tais como aprovação, desconveniamento e aditamento; recursos para reforma, ampliação ou construção de Cras e Creas; aplicação dos recursos do IGD do PBF; definição de critérios de partilha de recursos e de transferência, como os pisos; e aprovação de relatórios de cumprimento do objeto de convênios.

O último subtema referiu-se à Prestação de contas dos respectivos fundos de assistência social, à aprovação do Demonstrativo Sintético Anual de Execução Físico-Financeiro no SuasWeb, assim como a trechos relacionados à reprogramação de saldos. 
EDITE DA PENHA CUNHA; ISABELLA LOURENÇO LINS; MÁRCIA MIRANDA SOARES

Posteriormente, buscou-se identificar, nos trechos de falas classificadas nesses subtemas, como o centralismo fiscal da política incidiu sobre a capacidade das IPs de tomar decisões e exercer o controle do financiamento da assistência social. Foram atribuídos o código 0 para efeito nulo ou contrário do esperado e o código 1 para efeitos observados, de fortalecimento ou constrangimento.

\begin{abstract}
Federalism and social assistance councils: an analysis from financing

Federalism and social participation are relevant themes in public policy studies. However, there is little dialogue between these themes, a gap that this article aims to minimize when analyzing the effects of fiscal centralization of social assistance on the functioning and results produced by the councils. Would the federative dynamics of this policy also be reproduced in the councils, differentiating national and subnational institutions? To answer this question, the article adopts qualitative analysis to identify the strengthening or the constraint of fiscal centralism in excerpts of 658 minutes and 2,364 resolutions of five cases: CNAS; the state councils of Minas Gerais and Rio Grande do Sul; and the municipalities of Belo Horizonte and Porto Alegre. The results indicate that the strong regulation of social assistance and the concentration of expenditures at the central level have important effects, promoting the strengthening of CNAS and constraints to the work of subnational councils in the definition and control of this policy in their financing.
\end{abstract}

Keywords: federalism; participatory institutions; public policy councils; social assistance; financing

\title{
Resumen
}

Federalismo y consejos de asistencia social: un análisis a partir del financiamiento

El federalismo y la participación social son temas relevantes en los estudios de políticas públicas. Sin embargo, hay poco diálogo entre esos temas, brecha que ese artículo busca minimizar al analizar los efectos del centralismo fiscal de la asistencia social en el funcionamiento y resultado producidos por los consejos de políticas públicas. ¿La dinámica federativa de la política se reproduce también en los consejos, distinguindo las instituciones nacionales y subnacionales? Para responder a esta cuestión, el artículo adopta un análisis cualitativo para identificar el fortalecimiento o la limitación del centralismo fiscal en pasajes de 658 atas y 2.364 resoluciones de cinco casos seleccionados: el CNAS; los consejos estatales de Minas Gerais (MG) y Rio Grande do Sul (RS); y los municipales de Belo Horizonte (BH) y Porto Alegre (PoA). Los resultados encontrados indican que la fuerte regulación fiscal de la asistencia social y la concentración de gastos a nível central tienen importantes efectos, promoviendo el fortalecimiento del CNAS y limitaciones a la atuación de los consejos subnacionales en la definición y control de la assistência social en su financiamento.

Palabras clave: federalismo; instituciones participativas; consejos de políticas públicas; asistencia social; financiamiento

\section{Résumé}

Fédéralisme et conseils de l'assistance sociale: une analyse du financement

Le fédéralisme et la participation sociale sont des thèmes pertinents dans les études de politique publique. Cependant, il y a peu de dialogue entre ces thèmes, une lacune que cet article cherche à minimiser lors de l'analyse des effets de la centralisation fiscale de l'assistance sociale sur le fonctionnement et les résultats produits par les conseils. La dynamique fédératrice de cette politique serait-elle également reproduite dans les conseils, en différenciant les institutions nationales et sous-nationales? Pour répondre à cette question, l'article adopte une analyse qualitative visant à identifier le renforcement ou la contrainte du centralisme fiscal 
dans des extraits de 658 minutes et 2364 résolutions de cinq affaires: CNAS; les conseils d'état de Minas Gerais et du Rio Grande do Sul; et les municipalités de Belo Horizonte et Porto Alegre. Les résultats indiquent que la réglementation stricte de l'assistance sociale et la concentration des dépenses au niveau central ont des effets importants, favorisant le renforcement de la CNAS et limitant le travail des conseils infranationaux dans la définition et le contrôle de cette politique dans leur financement.

Mots-clés: fédéralisme; institutions participatives; conseils de politique publique; assistance sociale; financement

Artigo submetido à publicação em 13 de fevereiro de 2019. Versão final aprovada em 5 de fevereiro de 2020.

Opinião Pública adota a licença Creative Commons CC-BY. 